\title{
A systematic review of the clinical effectiveness of 64-slice or higher computed tomography angiography as an alternative to invasive coronary angiography in the investigation of suspected coronary artery disease
}

\author{
Daniel C Paech ${ }^{*}$ and Adèle R Weston
}

\begin{abstract}
Background: This systematic review summarized recent evidence pertaining to the clinical effectiveness of 64-slice or higher computed tomography angiography (CTA) in patients with suspected coronary artery disease (CAD). If CTA proves to be a successful diagnostic performance measure, it could prevent the use of invasive diagnostic procedures in some patients. This would provide multiple health and cost benefits, particularly for under resourced areas where invasive coronary angiography is not always available.
\end{abstract}

Methods: A systematic method of literature searching and selection was employed with searches limited to December 2006 to March 2009. Included studies were quality assessed using National Health and Medical Research Council (NHMRC) diagnostic levels of evidence and a modified Quality Assessment of Diagnostic Accuracy Studies (QUADAS) tool. Individual and pooled diagnostic performance measures were calculated using standard meta-analytic techniques at the patient, vessel and segment level. A positive result was defined as greater than or equal to $50 \%$ stenosis.

Results: Twenty-eight studies were included in the systematic review examining 3,674 patients. The primary metaanalysis at the patient-level indicated a sensitivity of $98.2 \%$ and specificity of $81.6 \%$. The median (range) positive predictive value (PPV) was 90.5\% (76\%-100\%) and negative predictive value (NPV) 99.0\% (83\%-100\%). In all vessels, the pooled sensitivity was 94.9\%, specificity 89.5\%, and median (range) PPV 75.0\% (53\%-95\%) and NPV 99.0\% (93\%100\%). At the individual artery level, overall diagnostic accuracy appeared to be slightly higher in the left main coronary artery and slightly lower in the left anterior descending and circumflex artery. In all segments, the sensitivity was 91.3\%, specificity $94.0 \%$ and median (range) PPV 69.0\% (44\%-86\%) and NPV 99.0\% (98\%-100\%).

Conclusions: The high sensitivity indicates that CTA can effectively identify the majority of patients with significant coronary artery stenosis. The high NPV at the patient, vessel and segment level establishes CTA as an effective noninvasive alternative to invasive coronary angiography (ICA) for the exclusion of stenosis.

\section{Background}

Coronary artery disease (CAD) is the leading cause of death and disability in the U.S. and other Western countries [1]. Detecting and assessing the extent of CAD has become increasingly important so that early intervention can be applied to decrease morbidity and mortality.

\footnotetext{
* Correspondence: dpaech@htanalysts.com
Health Technology Analysts Pty Ltd, 135 Rowntree St, Balmain NSW 2041,

* Correspondence: dpaech@htanalysts.com
Health Technology Analysts Pty Ltd, 135 Rowntree St, Balmain NSW 2041, Australia
}

(c) 2011 Paech and Weston; licensee BioMed Central Ltd. This is an Open Access article distributed under the terms of the Creative Commons Attribution License (http://creativecommons.org/licenses/by/2.0), which permits unrestricted use, distribution, and reproduction in any medium, provided the original work is properly cited. electrocardiogram (ECG) is normally performed in the first instance. If this is normal or equivocal, an exercise stress test will usually follow. If this remains inconclusive, invasive coronary angiography (ICA) is often performed. ICA allows ad hoc performance of coronary interventions such as percutaneous coronary intervention (PCI), however only one third of all ICAs are performed in conjunction with a revascularisation 
procedure, whilst the rest are performed only for diagnostic purposes [2].

Due partly to its high cost, but also because of the associated mortality and morbidity, it has been suggested that ICA is not ideal as a widespread diagnostic procedure thus prompting interest in the development of non-invasive coronary imaging [3]. The most serious complications of ICA are death (0.1-0.2\%), non-fatal myocardial infarction (MI) $(0.1 \%)$ and cerebrovascular accidents (0.1\%) [4-6]. Other complications include arrhythmias, vasovagal reactions, infections and allergic dye reactions. Exercise ECG is widely used for non-invasive detection of CAD owing to its ready availability and relatively low cost [7]. Other non-invasive techniques such as computed tomography angiography (CTA) have been developed to assist in the risk assessment process. At present, CTA is mainly used for detecting or excluding significant coronary stenosis $(\geq 50 \%$ diameter reduction) in coronary arteries. Recently, there has been considerable enhancement in temporal and spatial resolution, which has been reported to result in clinical benefit in terms of improved diagnostic accuracy [8]. The newer multi-detector machines can produce more images in less time, thereby increasing throughput and theoretically decreasing the cost per patient.

Despite this, owing mainly to its high temporal and spatial resolution, ICA remains the diagnostic criterion standard for clinical evaluation of known or suspected CAD. It is conducted both to assist with determining the extent of CAD and to help guide cardiac interventions to treat these disorders. Although CTA is less invasive, carries a lower risk of serious complications, and is cheaper than ICA, concerns about its accuracy in excluding patients without significant stenosis has prevented it becoming a diagnostic test of choice for clinicians [9].

This systematic review aimed to summarise recent evidence pertaining to the clinical effectiveness of 64-slice CTA in patients with suspected CAD. While true that it is based on a previous systematic review, this study provides the most recent diagnostic performance information from studies of 64-slice CT angiography in patients with suspected CAD. It is important to note there has been a significant volume of new literature published on this topic in recent years. If CTA proves to be a successful diagnostic performance measure, it could prevent the application of invasive diagnostic procedures in some patients. It may be of particular value in settings where patients do not have ready access to ICA.

\section{Methods}

\section{Literature search}

This systematic review, commissioned by the New Zealand Ministry of Health, was based on a previous health technology assessment (HTA) of the clinical effectiveness and cost-effectiveness of 64-slice or higher CTA as an alternative to ICA in the investigation of CAD [10]. The HTA report had a search date end of December 2006. For this review, searches were limited to English language material published from between December 2006 and March 2009. The primary computerized search was conducted by cross-searching EMBASE, Medline, the Cochrane library and HTA databases. Individual search strategies for each electronic database, using relevant subject headings, were undertaken based on the literature search by Mowatt et al [10]. These included the following keywords: coronary artery disease, myocardial ischemia, ischemic heart disease, myocardial infarction, chest pain, angina, stenosis, computed tomography, computer assisted tomography, computed tomographic angiography, invasive coronary angiography and coronary angiogram.

\section{Study eligibility}

Titles and abstracts of identified studies were screened for possible inclusion or exclusion before retrieving full text versions of the publications. Included studies were those that compared the diagnostic accuracy of CTA to ICA in patients with suspected CAD. As opposed to the broader review by Mowatt et al [10], this review did not include prognostic studies, technical studies (e.g. image quality), assessment studies, or post-revascularisation studies. Citations were excluded if they were reported as a conference abstract, not a diagnostic performance study; they included the wrong intervention (i.e. not 64slice or higher CTA); they did not report diagnostic performance results relating to the identified outcome of interest ( $\geq 50 \%$ stenosis); or if they had fewer than 50 study participants receiving both CTA and the reference standard. Double-checking of the eligibility of studies by a second reviewer was not undertaken.

Part of the criteria for determining study eligibility was that articles reported either the absolute number of true positives, false positives, false negatives and true negatives, or sensitivity and specificity. Due to the nature of CTA, this could have been presented at the patient, vessel or segment level. Some papers reported diagnostic performance results for individual coronary arteries including the right coronary artery, left coronary artery, left anterior descending and circumflex artery. Most reported the results for all segments with some papers breaking this down further to proximal and distal segments, or side branches.

The level of analysis has implications for clinical practice. Patient-level results are the most important from a patient management perspective because if a significant stenosis is successfully detected then that patient will be referred for an ICA. If results suggest no significant 
stenosis, then theoretically the patient would not require an ICA and would continue with conservative management. At the vessel-level, if a significant stenosis is detected in a certain artery (i.e. left anterior descending artery), this will better inform the clinician who is to perform the forthcoming intervention. The segmentlevel analysis is valuable to gauge the diagnostic precision of the technology and can also provide useful information for a re-vascularisation procedure, if it is required.

\section{Appraisal of included studies}

Each of the included studies was reviewed and assigned a level of evidence in accordance with the National Health and Medical Research Council (NHMRC) of Australia diagnostic levels of evidence [11]. In addition, in accordance with the review by Mowatt and colleagues [10], individual study quality for this update was assessed using a modified version of the Quality Assessment of Diagnostic Studies (QUADAS) tool. Quality criteria were tabulated in the data extraction form, rather than used to formulate a numeric score.

\section{Equivocal test results}

The classification of equivocal test results is important in diagnostic intervention studies as it influences the sensitivity, specificity, PPV, NPV and overall diagnostic accuracy of the test. By definition it is the equivocal tests that are most likely to be misclassified. There was considerable variation in how equivocal results were handled in the included studies. Some studies in the current review treated equivocal results as test positive (where the true disease status was known), some as false positive, and some excluded equivocal tests from the analysis completely. Where the true disease status is presented for equivocal test results but not included in the diagnostic performance measures, the reviewer has re-calculated these measures. Excluding equivocal results is the least preferred methodology as it can bias results in favour of the test. In addition, in clinical practice, patients with either positive CTA results or non-evaluable test results will most probably undergo ICA [12].

\section{Data extraction and data synthesis}

In the included studies, a positive CTA or ICA test was defined as $\geq 50 \%$ stenosis. Data were extracted by one reviewer onto specifically designed data extraction forms. The sensitivity and specificity of CTA at the patient-level were meta-analysed using Review Manager Version 5.0 and Metadisc Version 1.4. Pooled estimates were provided together with $95 \%$ confidence intervals of the estimate. The pooled estimates correspond to weighted averages in which the weight of each study is its sample size. Pooled confidence intervals are calculated using an F-distribution. In addition, an assessment of diagnostic threshold variation among studies was undertaken using a summary receiver operating characteristic (SROC) curve.

Pooled sensitivity and specificity and median (range) PPV, NPV and overall diagnostic accuracy results were calculated for: all vessels, individual coronary arteries (right coronary; left coronary; left anterior descending; and circumflex arteries) as well as all segments, using the equivocal test result selection methodology outlined above. The analysis of vessels did not include any subgroup analyses that limited results by vessel size. For patient-level analysis, forest plots were also included.

The base-case meta-analysis presented the diagnostic performance results of CTA at the patient-level but omitted studies that excluded equivocal test results. A second (alternative) meta-analysis included all studies that presented patient-level results with treatment of equivocal test results preferentially included as follows. The first preference was results (either as reported by authors or re-calculated by the reviewer) with equivocal CTA test results included and treated as test positive, with disease status as determined by ICA correctly assigned. The second preference was for results presented with equivocal test results treated as false positives (i.e. intent-to-diagnose principal). In this case the ICA result for equivocal segments was unknown and therefore could not be re-calculated. This convention assumes that the test was classified positive and the disease state negative. The third preference was for results presented with equivocal tests excluded.

\section{Results}

\section{Literature search}

There were 1,438 non-duplicate studies identified by the search strategy. Ninety nine full text articles were eligible for retrieval after excluding studies based on their title or abstract. Of the full papers retrieved, 71 did not fulfil the eligibility criteria and were excluded. Therefore, 28 articles examining 3,674 patients were included and fully appraised in this systematic review.

\section{Characteristics of the included studies}

The characteristics of the included studies are summarised in Table 1. Of the 28 included studies, nine were assessed as Level II diagnostic evidence, 15 were categorised as Level III-1 evidence, and four as Level III-2 evidence [8,12-38]. The majority were diagnostic intervention studies in which patients presenting with suspected CAD were prospectively analysed with 64slice CTA to determine whether or not they had significant stenosis of coronary arteries. In order to validate the CTA results, all the included studies required patients to undergo a conventional ICA, which in some 
Table 1 Summary of included study characteristics

\begin{tabular}{|c|c|c|c|c|c|c|c|}
\hline $\begin{array}{l}\text { Author } \\
\text { (Year) }\end{array}$ & Type of scanner & $\begin{array}{l}\text { Participants } \\
\text { analysed (n) }\end{array}$ & $\begin{array}{c}\text { Mean } \\
\text { age } \\
\text { (years) }\end{array}$ & $\begin{array}{l}\text { Gender } \\
\text { (M/F) }\end{array}$ & $\begin{array}{l}\text { Prevalence } \\
\text { of CAD (\%) }\end{array}$ & $\begin{array}{c}\text { Mean } \\
\text { heart rate } \\
( \pm \text { SD) } \\
(\text { bpm) }\end{array}$ & $\begin{array}{l}\text { Level of analysis } \\
\text { presented in publication }\end{array}$ \\
\hline
\end{tabular}

\begin{tabular}{|c|c|c|c|c|c|c|c|c|c|}
\hline & & & & & & \multirow{2}{*}{\multicolumn{2}{|c|}{ Patient }} & \multirow{2}{*}{ Vessel } & \multirow[b]{2}{*}{ Segment } \\
\hline & & & & & & & & & \\
\hline \multicolumn{10}{|c|}{ Level II diagnostic studies } \\
\hline $\begin{array}{l}\text { Brodoefel et } \\
\text { al (2008) [8] }\end{array}$ & Somatom Sensation 64, Siemens, Germany & 102 & 62.0 & $82 / 20$ & 62.7 & $68.2 \pm 13.3$ & No & No & Yes \\
\hline $\begin{array}{l}\text { Cademartiri } \\
\text { et al } \\
\text { (2008a) [13] }\end{array}$ & Somatom Sensation 64, Siemens, Germany & 170 & $57.5^{a}$ & $124 / 46$ & NR & $62.7 \pm 10.5$ & No & No & Yes \\
\hline $\begin{array}{l}\text { Ghostine et } \\
\text { al (2008) } \\
{[14]}\end{array}$ & Somatom Sensation 64, Siemens, Germany & 93 & 65.0 & $61 / 32$ & 46.0 & $73.0 \pm 14.0$ & Yes & No & Yes \\
\hline $\begin{array}{l}\text { Husmann et } \\
\text { al (2008) } \\
{[15]}\end{array}$ & Somatom Sensation 64, Siemens, Germany & 88 & 64.3 & $48 / 40$ & 48.9 & $63.0 \pm 9.2$ & Yes & Yes & Yes \\
\hline $\begin{array}{l}\text { Leber et al } \\
\text { (2007) [16] }\end{array}$ & Somatom Sensation 64, Siemens, Germany & 90 & 58.0 & $57 / 33$ & 47.7 & $73.0 \pm N R$ & Yes & No & Yes \\
\hline $\begin{array}{l}\text { Leschka et } \\
\text { al (2008a) } \\
{[17]}\end{array}$ & Somatom Sensation 64, Siemens, Germany & 74 & 61.7 & $50 / 24$ & 47.3 & $67.7 \pm 13.3$ & Yes & Yes & Yes \\
\hline $\begin{array}{l}\text { Leschka et } \\
\text { al (2008b) } \\
{[18]}\end{array}$ & Somatom Sensation 64, Siemens, Germany & 114 & 62.2 & $73 / 41$ & 62.3 & $68.0 \pm 13.0$ & Yes & No & Yes \\
\hline $\begin{array}{l}\text { Rixe et al } \\
\text { (2009) [19] }\end{array}$ & Somatom Sensation 64, Siemens, Germany & 76 & 65.5 & $47 / 29$ & 52.6 & $68.0 \pm 9.0$ & Yes & Yes & Yes \\
\hline $\begin{array}{l}\text { Shabestari } \\
\text { et al (2007) } \\
\text { [20] }\end{array}$ & Somatom Sensation 64, Siemens, Germany & 138 & 63.0 & $103 / 35$ & 78.3 & $65.0 \pm \underset{b}{ \pm} N R$ & Yes & Yes & Yes \\
\hline \multicolumn{10}{|c|}{ Level III-1 diagnostic studies } \\
\hline $\begin{array}{l}\text { Achenbach } \\
\text { et al (2008) } \\
\text { [21] }\end{array}$ & Somatom Sensation 64, Siemens Germany & 200 & 63.0 & $114 / 86$ & 44.5 & $76 \pm 13$ & Yes & Yes & Yes \\
\hline $\begin{array}{l}\text { Budoff et al } \\
\text { (2008) [22] }\end{array}$ & Lightspeed VCT Scanner, GE Healthcare & 230 & 57.0 & $136 / 94$ & 24.8 & $60 \pm 12$ & Yes & Yes & No \\
\hline $\begin{array}{l}\text { Cademartiri } \\
\text { et al (2007) } \\
\text { [23] }\end{array}$ & Somatom Sensation 64, Siemens, Germany & 72 & 53.9 & $38 / 34$ & 28.0 & $70.0 \pm 9.9$ & Yes & Yes & Yes \\
\hline $\begin{array}{l}\text { Hausleiter } \\
\text { et al (2007) } \\
{[24]} \\
\end{array}$ & $\begin{array}{c}\text { Somatom Sensation } 64 \text { Cardiac, Siemens, } \\
\text { Germany }\end{array}$ & 243 & 62.0 & $158^{c / 85}$ & 42.0 & $56.6 \pm 6.5$ & Yes & Yes & Yes \\
\hline $\begin{array}{l}\text { Herzog et al } \\
\text { (2007) [25] }\end{array}$ & Somatom Sensation 64, Siemens, Germany & 55 & 67.0 & $29 / 26$ & 34.5 & $64.0 \pm N R$ & Yes & Yes & Yes \\
\hline $\begin{array}{l}\text { Meijboom } \\
\text { et al } \\
\text { (2007a) [26] } \\
\end{array}$ & Somatom Sensation 64, Siemens, Germany & 104 & $58.7^{a}$ & $75 / 29$ & 85.0 & $66.0 \pm 9.0$ & Yes & Yes & Yes \\
\hline $\begin{array}{l}\text { Meijboom } \\
\text { et al } \\
\text { (2007b) [27] } \\
\end{array}$ & Somatom Sensation 64; Siemens, Germany & 402 & $59.2^{a}$ & $279 / 123$ & 62.9 & $\underset{N R}{59.5^{a} \pm}$ & Yes & Yes & Yes \\
\hline $\begin{array}{l}\text { Meijboom } \\
\text { et al } \\
\text { (2007c) [28] }\end{array}$ & Somatom Sensation 64, Siemens, Germany & 254 & $59.0^{a}$ & $171 / 83$ & 49.6 & $\underset{N R}{59.3^{a} \pm}$ & Yes & Yes & Yes \\
\hline $\begin{array}{l}\text { Meijboom } \\
\text { et al (2008) } \\
{[12]}\end{array}$ & $\begin{array}{c}\text { Somatom Sensation 64, Siemens, Germany; } \\
\text { Brilliance 64, Philips, The Netherlands; } \\
\text { Toshiba Multi-Slice Aquilion 64, Toshiba, } \\
\text { Japan }\end{array}$ & 360 & 60.0 & $245 / 115$ & 68.0 & $59 \pm 9$ & Yes & Yes & Yes \\
\hline $\begin{array}{l}\text { Oncel et al } \\
\text { (2007) [29] }\end{array}$ & Somatom Sensation 64, Siemens, Germany & 80 & 56.0 & $61 / 19$ & 77.5 & $58.0 \pm 10.0$ & Yes & No & Yes \\
\hline
\end{tabular}


Table 1 Summary of included study characteristics (Continued)

\begin{tabular}{|c|c|c|c|c|c|c|c|c|c|}
\hline $\begin{array}{l}\text { Piers et al } \\
(2008) \text { [30] }\end{array}$ & Somatom Sensation 64, Siemens, Germany & 60 & 64.0 & $51 / 9$ & 63.3 & $63.0 \pm 12.0$ & Yes & Yes & Yes \\
\hline $\begin{array}{l}\text { Scheffel et } \\
\text { al (2008) } \\
{[31]}\end{array}$ & Somatom Sensation 64, Siemens, Germany & 120 & 68.2 & $71 / 49$ & 55.0 & $59.0 \pm 6.0$ & Yes & Yes & Yes \\
\hline $\begin{array}{l}\text { Schlosser et } \\
\text { al (2007) } \\
{[32]}\end{array}$ & Somatom Sensation 64, Siemens, Germany & 61 & 62.4 & $41 / 20$ & NR & $57.0 \pm 4.0$ & No & Yes & Yes \\
\hline $\begin{array}{l}\text { Sheth et al } \\
\text { (2008) [33] }\end{array}$ & $\begin{array}{l}\text { Toshiba Aquilion 64-detector scanner, } \\
\text { Toshiba, Japan }\end{array}$ & 80 & 56.0 & $43 / 37$ & 39.5 & NR & Yes & Yes & Yes \\
\hline $\begin{array}{l}\text { Weustink et } \\
\text { al (2007) } \\
{[34]}\end{array}$ & $\begin{array}{l}\text { DSCT Somatom Sensation 64, Siemens, } \\
\text { Germany. }\end{array}$ & 100 & 61.0 & $79 / 21$ & 77.0 & $68.0 \pm 11.0$ & Yes & Yes & Yes \\
\hline \multicolumn{10}{|c|}{ Level III-2 diagnostic studies } \\
\hline $\begin{array}{l}\text { Cademartiri } \\
\text { et al } \\
(2008 b)[35]\end{array}$ & $\begin{array}{c}\text { Somatom Sensation } 64 \text { Cardiac; Siemens, } \\
\text { Germany }\end{array}$ & 134 & 63.4 & $98 / 36$ & 62.7 & ${ }_{N R}^{57.5^{a} \pm}$ & Yes & Yes & Yes \\
\hline $\begin{array}{l}\text { Han et al } \\
\text { (2008) [36] }\end{array}$ & 64-slice VCT; GE Healthcare & 53 & 59.6 & $\begin{array}{c}228 \mathrm{~d} / \\
175\end{array}$ & 81.1 & NR & No & No & Yes \\
\hline $\begin{array}{l}\text { Pugliese et } \\
\text { al (2008) } \\
{[37]}\end{array}$ & Somatom Sensation 64, Siemens, Germany & 51 & 59.0 & $39 / 12$ & 74.5 & $58.0 \pm 7.0$ & Yes & No & Yes \\
\hline $\begin{array}{l}\text { Yoshida et } \\
\text { al (2009) } \\
{[38]}\end{array}$ & Somatom Sensation 64, Siemens, Germany & 70 & 64.0 & $50 / 20$ & NR & $65.0 \pm 11.0$ & No & No & Yes \\
\hline
\end{tabular}

Bpm, beats-per-minute; $C A D$, coronary artery disease; F, female; $M$, male; NR, not reported.

Levels of evidence were defined according to the NHMRC diagnostic levels of evidence (11)

a Calculated post hoc using a crude weighted average of the two reported sub-groups

${ }^{b}$ Median heart rate

c There was a discrepancy between the number stated in Table 1 of the publication and the number stated in the text (228 and 226 , respectively).

${ }^{\mathrm{d}}$ For all enrolled patients in study

cases was performed prior to the 64-slice CTA. In all studies, however, the ICA was performed independently of the CTA, and with the exception of two studies, it was clear that the results of the index test had been interpreted by a reviewer blinded to the results of the reference standard.

Of the included studies, nine recruited patients consecutively whereas 17 either recruited patients non-consecutively or did not report the method of recruitment and were consequently assumed to have recruited nonconsecutively. Two included studies were retrospective analyses. In accordance with eligibility criteria determined a priori, each included study examined more than 50 patients, with the number of participants analysed ranging from 51 to 402 . Consistent with the gender and demographic profile for CAD, more males than females were examined in the included studies with mean age ranging from 53.9 to 68.2 years.

The eligibility criteria of the included studies were similar throughout. Although most studies did not explicitly report inclusion criteria, the study populations included patients with suspected CAD because of a range of symptoms (e.g. angina), usually scheduled for ICA. Those who had undergone a previous PCI such as stenting or CABG were excluded. Patients who had a contraindication to CTA such as a known allergy to iodinated contrast agent were also excluded. Other common exclusion criteria included atrial fibrillation, impaired renal function and inability to follow the breath hold command required to complete the test. There were no exclusions of patients based on significant calcification of the arteries. The majority of patients were given beta-blockers prior to scanning in order to reduce their heart rate.

The prevalence of CAD in the included study cohorts ranged from $24.8 \%-85.0 \%$. The lowest prevalence (24.8\%) came from the study by Budoff et al [22] who examined patients presenting with typical or atypical chest pain, who were being referred for ICA. The highest prevalence came from a study by Meijboom and colleagues [26] who investigated high and low risk non-ST segment elevation in acute coronary syndrome patients with a positive or inconclusive exercise ECG test or high suspicion for CAD. Patients presenting with STsegment elevation MI were excluded. Five other included studies had a prevalence of CAD above $70.0 \%$. All five included patients presenting with typical or atypical chest pain but two studies also included patients 
with unstable angina. Although all 28 included studies examined patients suspected of having CAD, the variation in prevalence reflects the level of suspicion of significant stenosis.

\section{Diagnostic accuracy of CTA}

Forest plots with the associated sensitivity, specificity, PPV and NPV of CTA for detecting significant stenosis for the patient-level base case meta-analysis are shown in Figure 1 and Figure 2. The pooled value (95\% CI) for sensitivity and specificity and median (range) for PPV, NPV and overall diagnostic accuracy for all levels of analysis (i.e. patient, vessel and segment level) are presented in Table 2.

At the patient-level, there were 18 studies included in the base case meta-analysis and 22 studies included in the alternative meta-analysis. Omitting studies that excluded equivocal test results (i.e. the base case), sensitivity in the included studies ranged from $90.9 \%$ to $100.0 \%$, with a pooled sensitivity of $98.2 \%$ (97.4\%-98.8\%). Specificity ranged from $45.5 \%$ to $100.0 \%$, with a pooled specificity of $81.6 \%$ (79.0\%-84.0\%). The median PPV for the included studies was $90.5 \%(75.5 \%-100.0 \%)$, with the median NPV 99.0\% (83.3\%-100.0\%). There was little difference between the results of the base case and the alternative analysis.

At the overall vessel-level, omitting studies that excluded equivocal test results, sensitivity ranged from $87.3 \%$ to $100.0 \%$, specificity $68.0 \%$ to $97.1 \%$, PPV $53.4 \%$ to $95.0 \%$, NPV $92.7 \%$ to $100.0 \%$, and overall diagnostic accuracy from $73.8 \%$ to $98.0 \%$. The results for overall vessel-level analysis showed that the diagnostic performance is similar to that of the patient-level analysis with a high pooled sensitivity and median NPV (94.9\% and 99.0\%, respectively). The sensitivity for the right coronary artery

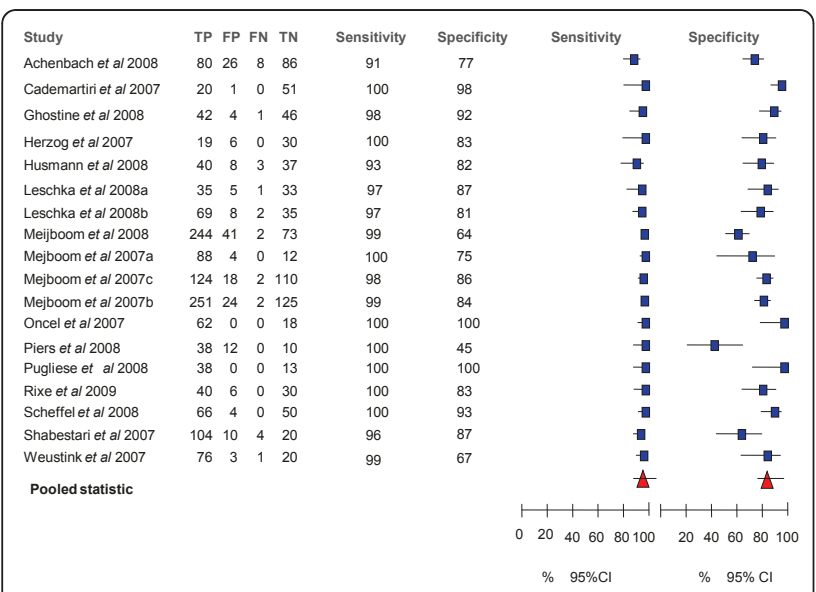

Figure 1 Sensitivity and specificity for the base case metaanalysis at the patient level. $\mathrm{Cl}$, confidence interval; $\mathrm{FN}$, false negative; $F P$, false positive; TN, true negative; TP, true positive.

\begin{tabular}{|c|c|c|c|c|c|c|c|c|}
\hline Study & TP & FP & $\mathrm{FN}$ & TN & PPV & NPV & PPV & NPV \\
\hline Achenbach et $a / 2008$ & 80 & 26 & 8 & 86 & 75 & 91 & घ & घ \\
\hline Cademartiri et al 2007 & 20 & 1 & 0 & 51 & 95 & 100 & I & I \\
\hline Ghostine et al 2008 & 42 & 4 & 1 & 46 & 91 & 98 & प & ! \\
\hline Herzog et al 2007 & 19 & 6 & 0 & 30 & 76 & 100 & ! & ! \\
\hline Husmann et al 2008 & 40 & 8 & 3 & 37 & 83 & 93 & 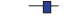 & प \\
\hline Leschka et al 2008a & 35 & 5 & 1 & 33 & 88 & 97 & + & $\square$ \\
\hline Leschka et al 2008b & 69 & 8 & 2 & 35 & 90 & 95 & - & ष \\
\hline Meijboom, Meijs 2008 & 244 & 41 & 2 & 73 & 86 & 97 & घ & ! \\
\hline Mejboom et al 2007a & 88 & 4 & 0 & 12 & 96 & 100 & - & ष \\
\hline Mejboom et al $2007 c$ & 124 & 18 & 2 & 110 & 87 & 98 & - & I \\
\hline Mejboom et al 2007b & 251 & 24 & 2 & 125 & 91 & 98 & - & ! \\
\hline Oncel et al 2007 & 62 & 0 & 0 & 18 & 100 & 100 & E & ๘ \\
\hline Piers et al 2008 & 38 & 12 & 0 & 10 & 76 & 100 & - & घ \\
\hline Pugliese et al 2008 & 38 & 0 & 0 & 13 & 100 & 100 & 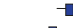 & 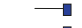 \\
\hline Rixe et $a / 2009$ & 40 & 6 & 0 & 30 & 87 & 100 & - & घ \\
\hline Scheffel et al 2008 & 66 & 4 & 0 & 50 & 94 & 100 & $\square$ & - \\
\hline Shabestriet al 2007 & 104 & 10 & 4 & 20 & 91 & 83 & - & ! \\
\hline Weustink et al 2007 & 76 & 3 & 1 & 20 & 96 & 95 & घ & प \\
\hline
\end{tabular}

Figure 2 PPV and NPV for the base case met-analysis at the patient level. $\mathrm{Cl}$, confidence interval; $\mathrm{FN}$, false negative; FP, false positive; TN, true negative; TP, true positive.

(RCA) ranged from $89.5 \%$ to $100.0 \%$, specificity $72.2 \%$ to 99.5\%, PPV $72.5 \%$ to $94.4 \%$, NPV $95.1 \%$ to $100.0 \%$ and overall diagnostic accuracy $83.7 \%$ to $99.0 \%$. For the left main (LM) artery, the sensitivity ranged from $83.3 \%$ to $100.0 \%$, specificity $91.1 \%$ to $100.0 \%$, PPV $23.8 \%$ to $100.0 \%$, NPV $97.6 \%$ to $100.0 \%$, and overall diagnostic accuracy $90.9 \%$ to $100.0 \%$. For the left anterior descending (LAD) artery, the sensitivity ranged from $93.8 \%$ to $100.0 \%$, specificity $55.8 \%$ to $92.7 \%$, PPV $57.1 \%$ to $95.0 \%$, NPV $95.0 \%$ to $100.0 \%$ and overall diagnostic accuracy $71.9 \%$ to $99.0 \%$. For the circumflex (CX) artery, the sensitivity ranged from $86.6 \%$ to $100.0 \%$, specificity $70.3 \%$ to 91.5\%, PPV $51.5 \%$ to $89.7 \%$, NPV $94.7 \%$ to $100.0 \%$ and overall diagnostic accuracy $75.3 \%$ to $99.0 \%$.

Pooled sensitivity remained high for each individual vessel $(94.1 \%$ to $97.4 \%)$. Specificity was slightly higher in the LM artery $97.1 \%(95.7 \%-98.1 \%)$ and slightly lower in the LAD artery $84.5 \%(82.1 \%-86.7 \%)$ compared with the other arteries. The median PPV was similar across vessels except for the LM, in which it was slightly higher 89.0\% (24.0\%-100.0\%). The median NPV was consistently high in each vessel (98.5\% to $100.0 \%)$.

At the segment-level, sensitivity ranged from $80.7 \%$ to $100.0 \%$, specificity $90.2 \%$ to $99.1 \%$, PPV $43.6 \%$ to $86.4 \%$, NPV $97.9 \%$ to $100.0 \%$ and overall diagnostic accuracy ranged from $90.0 \%$ to $99.1 \%$. There were 17 studies reporting overall segment level results. The pooled sensitivity was $91.3 \%(90.2 \%-92.2 \%)$, specificity $94.0 \%$ (93.7\%-94.2\%), PPV 69.0\% (44.0\%-86.0\%), NPV 99.0\% (98.0-100.0\%) and overall diagnostic accuracy $95.5 \%$ (90.0\%-99.0\%).

\section{Diagnostic threshold effect}

To assess the impact of diagnostic threshold variation between studies a symmetrical SROC curve was fitted 
Table 2 CTA diagnostic performance measures

\begin{tabular}{lcccccc}
\hline Analysis level & $\begin{array}{c}\text { No. of included } \\
\text { studies }^{\mathbf{a}}\end{array}$ & $\begin{array}{c}\text { Sensitivity \% } \\
\mathbf{( 9 5 \%} \mathbf{C l})\end{array}$ & $\begin{array}{c}\text { Specificity \% } \\
\mathbf{( 9 5 \% ~ C l )}\end{array}$ & $\begin{array}{c}\text { PPV Median } \\
\text { (range) }\end{array}$ & $\begin{array}{c}\text { NPV Median } \\
\text { (range) }\end{array}$ & $\begin{array}{c}\text { Diagnostic accuracy } \\
\text { Median (range) }\end{array}$ \\
\hline $\begin{array}{l}\text { Patient: base case } \\
\text { analysis }\end{array}$ & 18 & $98.2(97.4-98.8)$ & $81.6(79.0-84.0)$ & $90.5(76-100)$ & $99.0(83-100)$ & $92.0(80-100)$ \\
\hline $\begin{array}{l}\text { Patient: alternative } \\
\text { analysis }\end{array}$ & 22 & $98.0(97.2-98.6)$ & $83.2(81.1-85.2)$ & $89.0(63-100)$ & $98.0(83-100)$ & $92.0(80-100)$ \\
\hline Vessels: all & 17 & $94.9(93.9-95.8)$ & $89.5(88.8-90.2)$ & $75.0(53-95)$ & $99.0(93-100)$ & $91.5(74-98)$ \\
\hline \multicolumn{1}{c}{ RCA } & 8 & $94.8(92.0-96.9)$ & $91.0(89.0-92.7)$ & $84.0(73-94)$ & $98.5(95-100)$ & $94.5(84-99)$ \\
\hline \multicolumn{1}{c}{ LM } & 8 & $95.7(85.2-99.5)$ & $97.1(95.7-98.1)$ & $89.0(24-100)$ & $100.0(98-100)$ & $99.0(91-100)$ \\
\hline \multicolumn{1}{c}{ LAD } & 7 & $97.4(95.3-98.8)$ & $84.5(82.1-86.7)$ & $78.0(57-95)$ & $99.0(95-100)$ & $93.0(72-99)$ \\
\hline \multicolumn{1}{c}{ CX } & 8 & $94.1(90.7-96.6)$ & $89.6(87.7-91.3)$ & $78.5(52-90)$ & $99.5(95-100)$ & $94.0(75-99)$ \\
\hline Segments: all & 17 & $91.3(90.2-92.2)$ & $94.0(93.7-94.2)$ & $69.0(44-86)$ & $99.0(98-100)$ & $95.5(90-99)$
\end{tabular}

$\mathrm{Cl}$, confidence interval; $\mathrm{CX}$, circumflex; LAD, left anterior descending; LM, left main; NPV, negative predictive value; PPV, positive predictive value; RCA, right coronary artery

${ }^{a}$ Maximum number of included studies from which data were drawn to calculate diagnostic performance measures

(Figure 3). The area under the curve ( \pm SE) was 0.976 $( \pm 0.014)$, suggesting that variations in definition of a positive CTA result did not have an influence on the pooled sensitivity and specificity results.

\section{Discussion}

There has been considerable enhancement in temporal and spatial resolution of CTA in recent years, and these improvements appear to have contributed to the fact that CTA now preserves a high rate of evaluable patients. This systematic review summarized, through meta-analysis, recent clinical evidence pertaining to the use of 64-slice CTA in patients with suspected CAD.

The most important results from a patient management perspective are the patient-level results. If this technology is to be used successfully as a triage tool then any patient without significant stenosis would not be referred for an ICA. This may be of particular value when access to ICA is limited. The pooled estimate (95\% CI) of sensitivity was high with CTA correctly identifying the majority of patients who had a significant stenosis (98.2\%, 97.4\%-98.8\%). Perhaps more

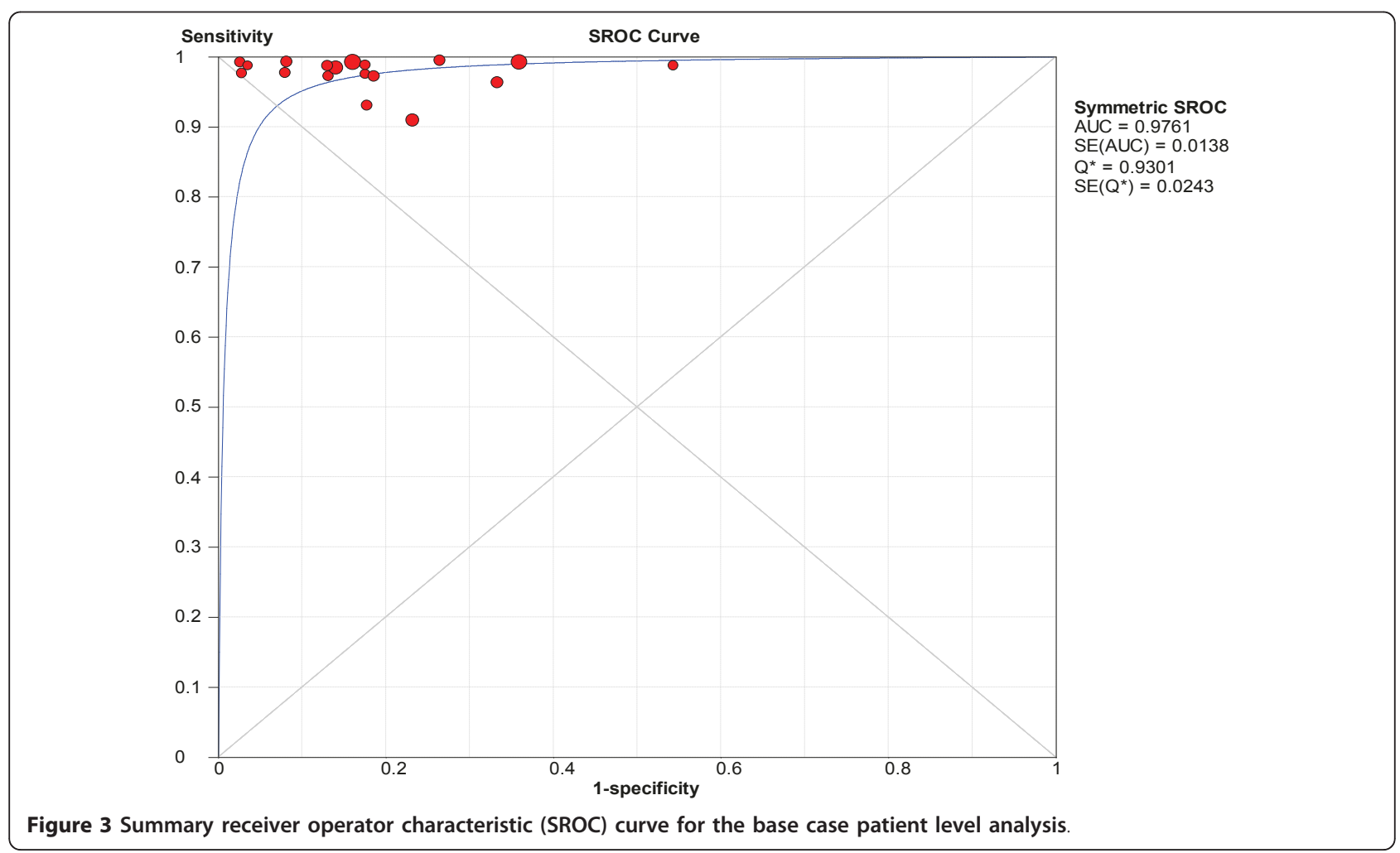


importantly, the median (range) NPV was very high (99.0\%, 83-100\%). NPV was above $95.0 \%$ in 14 of 18 included studies, and above $90.0 \%$ in 17 of 18 included studies suggesting that it can reliably exclude patients that test negative as not having significant stenosis. The only exception was the NPV result reported in Shabestri et al [20] where the NPV was $83.0 \%$. No reasons were offered by the authors as to why NPV was lower than in previously reported studies. This study had a high prevalence of CAD and subsequently a relatively low number of patients classified as true negative, which may have been why the false negative findings (four in total) significantly influenced the NPV.

The results of the current review were similar to that reported by Mowatt et al [10], the systematic review that the current review sought to update. Those authors found that sensitivity ranged from $94 \%$ to $100 \%$ with a pooled sensitivity of $99 \%$ (95\% credible interval (CrI) $97.0 \%$ to $99.0 \%)$. Specificity ranged from $50.0 \%$ to $100.0 \%$, with a pooled specificity of $89.0 \%$ (95\% CrI $83.0 \%$ to $94.0 \%)$. Across studies the median PPV was 93.0\% (range $64.0 \%$ to $100.0 \%$ ), while the median NPV was $100.0 \%$ (range $86.0 \%$ to $100.0 \%$ ). Comparisons with this review are limited by the fact that Mowatt and colleagues [10] included patient populations with both suspected and known CAD, rather than just suspected CAD as was the case in the present review. A further six systematic reviews were identified on this topic, all of which had been published during or prior to 2008 [39-44]. Although the reviews varied slightly in terms of their inclusion criteria and analyses, the broad conclusions were consistent with the current systematic review. The reviews suggested high diagnostic accuracy of CTA validates this scanning technique as an alternative to coronary angiography in populations suspected for coronary stenosis.

It has been suggested that CTA may be able to replace other non-invasive diagnostic imaging modalities such as myocardial perfusion scintigraphy (MPS) and stress ECG. A systematic review of single photon emission computed tomography (SPECT) MPS and stress ECG for the diagnosis and management of angina and MI, found sensitivity ranged from $63.0 \%$ to $93.0 \%$ (median $81.0 \%$ ) for SPECT and from $42.0 \%$ to $92.0 \%$ (median $65.0 \%$ ) for stress ECG. Specificity ranged from $10.0 \%$ to 90.0\% (median $65.0 \%$ ) for SPECT and $41.0 \%$ to $88.0 \%$ (median 67.0\%) for stress ECG [7]. The range and pooled estimate of sensitivity and specificity for the base-case meta-analysis was higher in the current review suggesting that CTA may have higher diagnostic accuracy than SPECT MPS and stress ECG in patients with suspected CAD.

The lowest specificity (45.5\%) and clear outlier in Figure 1 was reported by Piers et al [30]. The authors attributed this low percentage to the tendency of CTA to overestimate lesion severity (i.e. a large number of false positives). A lower specificity was generally related to difficulties in grading the severity of stenosis, particularly in studies that included all available segments regardless of image quality. The PPV was correlated with the variation in prevalence of CAD in each study cohort. As expected, those studies with a higher prevalence of CAD in the cohort tended to have higher PPVs.

The vessel level results are important because clinicians can identify which arteries contain significant stenosis and match potential re-vascularisation procedures accordingly. It is also important to know if CTA is particularly unreliable in a certain vessel. The pooled results for overall vessel-level analysis showed that the diagnostic performance is similar to that of the patientlevel analysis with a high sensitivity 94.9\% (93.9-95.8\%) and median NPV 99.0\% (93.0-100.0\%). Sensitivity remained high for each individual vessel. Specificity was slightly higher in the LM artery and slightly lower in the LAD artery, compared with the other arteries. The PPV was similar across vessels except for the LM artery, in which it was slightly higher. The NPV was consistently high in each vessel, suggesting that CTA is no less reliable at excluding significant stenosis in a particular artery.

The segment level results provide the most information on the overall technical accuracy of CTA in detecting significant stenosis in patients with suspected CAD. The sensitivity of the segment level analysis is lower than that of the vessel and patient-level analysis. This may be because there is an increased number of equivocal test results and therefore an increased proportion of incorrectly classified segments (i.e. false negatives). However, specificity is higher at the segment level, probably due to the increased number of true negatives being proportionally higher than the increase in false positives. PPV is significantly lower at the segment level compared with the patient-level because of the increased chance of poor image quality and therefore false positive outcomes. Also, because the conservative approach for clinicians reading CTA results is to treat equivocal tests as false positive. Similar to the other levels of analysis, NPV is high confirming the reliability of 64-slice CTA at excluding those without significant stenosis.

The evidence considered in this review exhibited some methodological limitations. A large variety of studies are included, such as studies dedicated to unstable populations, studies exploring different acquisition modes (prospective triggering) and as such caution should be warranted in interpreting results. Furthermore, the variability in prevalence of CAD in the included studies was a limitation, particularly because of the effect it had on the PPV. Although strict study eligibility and 
inclusion criteria were applied to try to minimise this, variations in the classification of suspected CAD by the authors of the included studies and subsequent variability in prevalence of disease could not be avoided. Futhermore, the current review does not address the willingness of clinicians to act upon negative CTA results to avoid referral to ICA.

In addition, no studies of 256-slice CTA met the inclusion criteria for the current review. Therefore, conclusions on the usefulness of 256-slice CTA in detecting significant stenosis cannot be made. Due to the abundance of studies conducted using 64-slice CTA since December 2006 and methodological issues with the meta-analyses of non-homogenous patient groups, the patient population investigated was restricted in the current review. As a consequence, the usefulness of CTA in asymptomatic patients or patients with known CAD was not examined.

\section{Conclusions}

Adoption of a new therapeutic strategy should be based on both clinical and cost-effectiveness. This review focused on the clinical effectiveness of CTA and results support previous findings that concluded that the main value of 64-slice CTA is to rule out significant CAD. The high NPV observed at the patient, vessel and segment level establishes CTA as a highly effective noninvasive alternative to ICA for the exclusion of obstructive coronary artery stenosis. It should also be noted, however, that overall diagnostic accuracy varied at the individual artery level, with results being slightly worse for the LAD and CX arteries compared with the RC and LM arteries. It is unlikely that CTA will replace ICA in assessment for revascularisation of patients, particularly as angiography and angioplasty are often performed on the same occasion. However, for those patients who are candidates for standalone diagnosis with ICA, CTA may be a viable alternative. Furthermore, in under serviced and under resourced health areas, where invasive coronary angiography is not always available, CTA appears a viable alternative.

\section{List of abbreviations}

CAD: Coronary artery disease; Crl: Credible interval; CTA: Computed tomography angiography; CX: Circumflex; ECG: Electrocardiogram; HTA: Health technology assessment; ICA: Invasive coronary angiography; MI: Myocardial infarction; NHMRC: National Health and Medical Research Council; NPV: Negative predictive value; PCl: Percutaneous coronary intervention; PPV: Positive predictive value; QUADAS: Quality assessment of diagnostic accuracy studies; RCA: Right coronary artery; LM: Left main; LAD: Left anterior descending

\section{Acknowledgements}

There are no sources of financial support or conflicts of interest to declare. The authors would like to acknowledge the New Zealand Ministry of Health and Sandy Dawson for their assistance directing and scoping the research project, Dr Niels van Pelt for clinical advice and guidance, Cecilia Tolan and
Lynn Wohlfiel for administrative support and Suzanne Campbell for assistance reviewing the manuscript. This research was commissioned and funded by the New Zealand Ministry of Health, however no funding was provided for the preparation of this manuscript.

\section{Authors' contributions}

All authors read and approved the final manuscript. The requirements for authorship stipulated by the International Committee of Medical Journal Editors have been met by all authors. DP contributed significantly to conception and design, contributed to the analysis and interpretation of data and drafted the article. AW contributed substantially to conception and design, revised the manuscript critically for important intellectual content and gave final approval for its publication.

\section{Competing interests}

The authors declare that they have no competing interests.

Received: 25 June 2010 Accepted: 16 June 2011

Published: 16 June 2011

\section{References}

1. American Heart Association: Heart Disease and Stroke Statistics: 2009 Update. Dallas, Texas. American Heart Association; 2009, 1-36.

2. Togni M, Balmer F, Pfiffner D, Maier W, Zeiher A, Meier B: Percutaneous coronary interventions in Europe 1992-2001. Eur Heart J 2004, 25:1208-1213.

3. Wittlinger $T$, Voigtlander T, Rohr M, Meyer J, Thelen M, Kreitner KF, Kalden P: Magnetic resonance imaging of coronary artery occlussions in the navigator technique. Int J Cardiovasc Imaging 2002, 18:203-211.

4. Gibbons RJ, Abrams J, Chatterjee K, Daley J, Deedwania PC, Douglas JS, Ferguson TB Jr, Fihn SD, Fraker TD Jr, Gardin JM, O'Rourke RA, Pasternak RC, Williams SV: ACC/AHA 2002 guideline update for the management of patients with chronic stable angina-summary article: a report of the American College of Cardiology/American Heart Association Task Force on Practice Guidelines (Committee on the Management of Patients With Chronic Stable Angina). Circulation 2003, 107:149-158.

5. Beers MH, Berkow R: The Merck manual of diagnosis and therapy. American College of Cardiology; 1999

6. National Horizon Scanning Centre: Imaging in Coronary Heart Disease. 2001 [http://www.haps.bham.ac.uk/publichealth/horizon/outputs/ documents/2001/lmaging.pdf].

7. Mowatt G, Vale L, Brazelli M, Hernandez R, Murray A, Scott N: Systematic review of the effectiveness and cost-effectiveness, and economic evaluation, of myocardial perfusion scintigraphy for the diagnosis and management of angina and myocardial infarction. Health Technol Assess 2004, 8:1-207.

8. Brodoefel H, Reimann A, Burgstahler C, Schumacher F, Herberts TM, Tsiflikas I, Schroeder S, Claussen CD, Kopp AF, Heuschmid M: Noninvasive coronary angiography using 64-slice spiral computed tomography in an unselected patient collective: Effect of heart rate, heart rate variability and coronary calcifications on image quality and diagnostic accuracy. Eur J Radiol 2008, 66:134-141.

9. National Institute for Health and Clinical Excellence: Computed tomography (CT) angiography for the diagnosis and management of coronary artery disease. 2007 [http://www.nice.org.uk/media/8A6/19/ CTCoronaryArteryDiseaseDraftScope.pdf].

10. Mowatt G, Cummins E, Waugh N, Walker S, Cook J, Jia X, Hillis GS, Fraser C: Systematic review of the clinical effectiveness and cost-effectiveness of 64-slice or higher computed tomography angiography as an alternative to invasive coronary angiography in the investigation of coronary artery disease. Health Technol Assess 2008, 12(17):iii-143.

11. Merlin T, Weston A, Tooher R: Extending an evidence hierarchy to include topics other than treatment: revising the Australian 'levels of evidence'. BMC Med Res Methodol 2009, 9(34):1-8.

12. Meijboom WB, Meijs MFL, Schuijf JD, Cramer MJ, Mollet NR, Van Mieghem CAG, Nieman K, van Werkhoven JM, Pundziute G, Weustink AC, de Vos AM, Pugliese F, Rensing B, Jukema JW, Bax JJ, Prokop M, Doevendans PA, Hunink MGM, Krestin GP, De Feyter PJ: Diagnostic accuracy of 64-slice computed tomography coronary angiography. A prospective, multicenter, multivendor study. J Am Coll Cardiol 2008, 52:2135-2144. 
13. Cademartiri F, Maffei E, Notarangelo F, Ugo F, Palumbo A, Lina D, Aldrovandi A, Solinas E, Reverberi C, Menozzi A, Vignali L, Malago R, Midiri M, Mollet NR, Cervellin G, Ardissino D: 64-slice computed tomography coronary angiography: Diagnostic accuracy in the real world. Radiol Med 2008, 113:163-180.

14. Ghostine S, Caussin C, Habis M, Habib Y, Clement C, Sigal-Cinqualbre A, Angel CY, Lancelin B, Capderou A, Paul JF: Non-invasive diagnosis of ischaemic heart failure using 64-slice computed tomography. Eur Heart $J$ 2008, 29:2133-2140.

15. Husmann L, Schepis T, Scheffel H, Gaemperli O, Leschka S, Valenta I, Koepfli P, Desbiolles L, Stolzmann P, Marincek B, Alkadhi H, Kaufmann PA: Comparison of Diagnostic Accuracy of 64-Slice Computed Tomography Coronary Angiography in Patients with Low, Intermediate, and High Cardiovascular Risk. Acad Radiol 2008, 15:452-461.

16. Leber AW, Johnson T, Becker A, von Ziegler F, Tittus J, Nikolaou K, Reiser M, Steinbeck G, Becker CR, Knez A: Diagnostic accuracy of dual-source multislice CT-coronary angiography in patients with an intermediate pretest likelihood for coronary artery disease. Eur Heart J 2007, 28:2354-2360.

17. Leschka S, Scheffel H, Desbiolles L, Plass A, Gaemperli O, Stolzmann P, Genoni M, Luescher T, Marincek B, Kaufmann P, Alkadhi H: Combining dual-source computed tomography coronary angiography and calcium scoring: Added value for the assessment of coronary artery disease. Heart 2008, 94:1154-1161.

18. Leschka S, Scheffel H, Husmann L, Gamperli O, Marincek B, Kaufmann PA, Alkadhi $\mathrm{H}$ : Effect of decrease in heart rate variability on the diagnostic accuracy of 64-MDCT coronary angiography. AJR Am J Roentgenol 2008, 190:1583-1590.

19. Rixe J, Rolf A, Conradi G, Moellmann H, Nef H, Neumann T, Steiger H, Hamm CW, Dill T: Detection of relevant coronary artery disease using dual-source computed tomography in a high probability patient series: comparison with invasive angiography. Cir J 2009, 73:316-322.

20. Shabestari AA, Abdi S, Akhlaghpoor S, Azadi M, Baharjoo H, Pajouh MD Emami Z, Esfahani F, Firouzi I, Hashemian M, Kouhi M, Mozafari M, Nazeri I, Roshani M, Salevatipour B, Tavalla H, Tehrai M, Zarrabi A: Diagnostic Performance of 64-Channel Multislice Computed Tomography in Assessment of Significant Coronary Artery Disease in Symptomatic Subjects. Am J Cardiol 2007, 99:1656-1661.

21. Achenbach S, Ropers U, Kuettner A, Anders K, Pflederer T, Komatsu S, Bautz W, Daniel WG, Ropers D: Randomized Comparison of 64-Slice Single- and Dual-Source Computed Tomography Coronary Angiography for the Detection of Coronary Artery Disease. JACC CardiovasC Imaging 2008, 1:177-186.

22. Budoff MJ, Dowe D, Jollis JG, Gitter M, Sutherland J, Halamert E, Scherer M, Bellinger R, Martin A, Benton R, Delago A, Min JK: Diagnostic Performance of 64-Multidetector Row Coronary Computed Tomographic Angiography for Evaluation of Coronary Artery Stenosis in Individuals Without Known Coronary Artery Disease. Results From the Prospective Multicenter ACCURACY (Assessment by Coronary Computed Tomographic Angiography of Individuals Undergoing Invasive Coronary Angiography) Trial. J Am Coll Cardiol 2008, 52:1724-1732.

23. Cademartiri F, Maffei E, Palumbo A, Malago R, Alberghina F, Aldrovandi A, Brambilla V, Runza G, La Grutta L, Menozzi A, Vignali L, Casolo G, Midiri M, Mollet NR: Diagnostic accuracy of 64-slice computed tomography coronary angiography in patients with low-to-intermediate risk. Radiologia Medica 2007, 112:969-981.

24. Hausleiter J, Meyer T, Hadamitzky M, Zankl M, Gerein P, Dorrler K, Kastrati A, Martinoff S, Schomig A: Non-invasive coronary computed tomographic angiography for patients with suspected coronary artery disease: The coronary angiography by computed tomography with the use of a submillimeter resolution (CACTUS) trial. Eur Heart J 2007, 28:3034-3041.

25. Herzog C, Zwerner PL, Doll JR, Nielsen CD, Nguyen SA, Savino G, Vogl TJ, Costello P, Schoepf UJ: Significant coronary artery stenosis: Comparison on per-patient and per-vessel or per-segment basis at 64-section CT Angiography. Radiology 2007, 244:112-120.

26. Meijboom WB, Mollet NR, Van Mieghem CA, Weustink AC, Pugliese F, van Pelt N, Cademartiri F, Vourvouri E, De Jaegere P, Krestin GP, De Feyter PJ: 64-Slice CT coronary angiography in patients with non-ST elevation acute coronary syndrome. Heart 2007, 93:1386-1392.

27. Meijboom WB, Weustink AC, Pugliese F, Van Mieghem CAG, Mollet NR, van Pelt N, Cademartiri F, Nieman K, Vourvouri E, Regar E, Krestin GP, De Feyter PJ: Comparison of diagnostic accuracy of 64-Slice computed tomography coronary angiography in women versus men with angina pectoris. Am J Cardiol 2007, 100:1532-1537.

28. Meijboom WB, Van Mieghem CAG, Mollet NR, Pugliese F, Weustink AC, van Pelt N, Cademartiri F, Nieman K, Boersma E, De Jaegere P, Krestin GP, De Feyter PJ: 64-Slice Computed tomography coronary angiography in patients with high, intermediate, or low pretest probability of significant coronary artery disease. J Am Coll Cardiol 2007, 50:1469-1475.

29. Oncel D, Oncel G, Tastan A, Tamci B: Detection of significant coronary artery stenosis with 64-section MDCT angiography. Eur J Radiol 2007, 62:394-405.

30. Piers LH, Dikkers R, Willems TP, De Smet BJGL, Oudkerk M, Zijlstra F, Tio RA: Computed tomographic angiography or conventional coronary angiography in therapeutic decision-making. Eur Heart J 2008, 29:2902-2907.

31. Scheffel H, Alkadhi H, Leschka S, Plass A, Desbiolles L, Guber I, Krauss T, Gruenenfelder J, Genoni M, Luescher TF, Marincek B, Stolzmann P: Lowdose CT coronary angiography in the step-and-shoot mode: Diagnostic performance. Heart 2008, 94:1132-1137.

32. Schlosser T, Mohrs OK, Magedanz A, Nowak B, Voigtlander T, Barkhausen J, Schmermund A: Noninvasive coronary angiography using 64-detectorrow computed tomography in patients with a low to moderate pretest probability of significant coronary artery disease. Acta radiol 2007, 48:300-307.

33. Sheth T, Amlani S, Lou Ellins M, Mehta S, Velianou J, Cappelli G, Yang S, Natarajan M: Computed tomographic coronary angiographic assessment of high-risk coronary anatomy in patients with suspected coronary artery disease and intermediate pretest probability. Am Heart J 2008, 155:918-923.

34. Weustink AC, Meijboom WB, Mollet NR, Otsuka M, Pugliese F, Van Mieghem C, Malago R, van Pelt N, Dijkshoorn ML, Cademartiri F, Krestin GP, De Feyter PJ: Reliable High-Speed Coronary Computed Tomography in Symptomatic Patients. J Am Coll Cardiol 2007, 50:786-794.

35. Cademartiri F, Maffei E, Palumbo AA, Malago R, Alberghina F, Aldrovandi A, Brambilla V, Runza G, La Grutta L, Menozzi A, Vignali L, Casolo G, Midiri M, Mollet NR: Influence of intra-coronary enhancement on diagnostic accuracy with 64-slice CT coronary angiography. Eur Radiol 2008, 18:576-583.

36. Han SC, Fang CC, Chen Y, Chen CL, Wang SP: Coronary computed tomography angiography - A promising imaging modality in diagnosing coronary artery disease. J Chin Med Assoc 2008, 71:241-246.

37. Pugliese F, Mollet NR, Hunink MGM, Cademartiri F, Nieman K, Van Domburg RT, Meijboom WB, Van Mieghem C, Weustink AC, Dijkshoorn ML, De Feyter PJ, Krestin GP: Diagnostic performance of coronary CT angiography by using different generations of multisection scanners: Single-center experience. Radiology 2008, 246:384-393.

38. Yoshida K, Shimada K, Tanaka A, Jissho S, Tanaka H, Yoshiyama M, Yoshikawa J: Quantitative analysis of myocardial contrast enhancement by first-pass 64-multidetector computed tomography in patients with coronary heart disease. Circ J 2009, 73:116-124.

39. Abdulla J, Abildstrom SZ, Gotzsche O, Christensen E, Kober L, TorpPedersen C: 64-Multislice detector computed tomography coronary angiography as potential alternative to conventional coronary angiography: A systematic review and meta-analysis. Eur Heart J 2007 28(24):3042-50.

40. Di Tanna GL, Berti E, Stivanello E, Cademartiri F, Achenbach S, Camerlingo MD, Grilli R: Informative value of clinical research on multislice computed tomography in the diagnosis of coronary artery disease: A systematic review. Int J Cardiol 2008, 130(3):386-404

41. Janne d'Othee B, Siebert U, Cury R, Jadvar H, Dunn EJ, Hoffmann U: A systematic review on diagnostic accuracy of CT-based detection of significant coronary artery disease. Eur J Radiol 2008, 65(3):449-61.

42. Stein PD, Yaekoub AY, Matta F, Sostman HD: 64-Slice CT for Diagnosis of Coronary Artery Disease: A Systematic Review. Am J Med 2008, 121(8):715-25

43. Sun Z, Lin C, Davidson R, Dong C, Liao Y: Diagnostic value of 64-slice CT angiography in coronary artery disease: A systematic review. Eur J Radiol 2008, 67(1):78-84.

44. Waugh N, Black C, Walker S, McIntyre L, Cummins E, Hillis G: The effectiveness and cost-effectiveness of computed tomography screening for coronary artery disease: Systematic review. Health Technol Assess 2006, 10(39):iii-38. 


\section{Pre-publication history}

The pre-publication history for this paper can be accessed here:

http://www.biomedcentral.com/1471-2261/11/32/prepub

doi:10.1186/1471-2261-11-32

Cite this article as: Paech and Weston: A systematic review of the clinical effectiveness of 64-slice or higher computed tomography angiography as an alternative to invasive coronary angiography in the investigation of suspected coronary artery disease. BMC Cardiovascular Disorders 2011 11:32

Submit your next manuscript to BioMed Central and take full advantage of:

- Convenient online submission

- Thorough peer review

- No space constraints or color figure charges

- Immediate publication on acceptance

- Inclusion in PubMed, CAS, Scopus and Google Scholar

- Research which is freely available for redistribution

Submit your manuscript at www.biomedcentral.com/submit 